\title{
TEORIA E SOFTWARE: REFLEXÕES SOBRE A DIVISÃO DE TRABALHO NAS LETRAS ONTEM E HOJE
}

\author{
Márcio Seligmann-Silva \\ Universidade Estadual de Campinas \\ m.seligmann@uol.com.br
}

\begin{abstract}
Resumo: O texto apresenta uma reflexão sobre a área de Letras, mas que vale para as ditas ciências humanas de um modo geral, que procura destacar o modo como se cria e circula a teoria hoje em dia. Partindo da ideia segundo a qual, para toda mudança de cânone deve ocorrer uma mudança de base teórica, diagnostica-se que, apesar da ampliação do cânone nas últimas décadas, nem a teoria se modificou suficientemente, nem a dinâmica da produção/consumo de teoria se alterou muito. Continua-se a produzir e exportar mais teoria (software) nos países ditos centrais e, por outro lado, a se consumir e traduzir essas teorias nos países ditos periféricos. Partindo de Flusser, o artigo conclui apontando para a necessidade de se criar novas linhas transnacionais de diálogos circulares e em rede, capazes de quebrar o predomínio norte $\rightarrow$ sul do discurso. O discurso central e sua importação/tradução devem ser substituídos por um diálogo horizontal com traduções de teoria nos dois sentidos.
\end{abstract}

Palavras-chave: dialogismo, redes, diálogo circular, ser como tradução.

\section{THEORY AND SOFTWARE: REFLECTIONS ABOUT THE DIVISION OF LABOR IN LITERARY STUDIES YESTERDAY AND TODAY}

\begin{abstract}
The article presents a reflection on the Literary Studies field, but that can also be applied to the humanities, that tries to emphasize how theory is created and circulates now a days. Departing from the idea that for all canon change it should also follow a shift at the theoretical basis,
\end{abstract}


the text diagnostic is that, although the canon was expanded during the last decades, theory did not went through a significant change, and also the dynamics of theory production/consumption did not change as it should. We still produce and export more theory (software) from the central countries and, at the same time, we consume and translate those theories in the peripheral ones. Departing from Vilém Flusser, the article concludes pointing to the need to create new transnational circular and network dialog ways, that will be able to break with the domination of north $\rightarrow$ south discourse. Central discourse and its importation/translation have to be substituted by a genuinely horizontal dialog with theory translation in both directions.

Keywords: dialogism, network, circular dialog, being as translation.

Toda teoria é filha de depuração feita a partir de fatos mais ou menos concretos. É, de certa forma, software derivado do hardware onde se funde natureza e cultura. A teoria da arte nasce de certas obras, e o leitor de teoria da literatura pode com certa facilidade identificar a que tradição determinada teoria diz respeito. Teoria é abstração feita a partir de obras que de algum modo são exemplares ou canônicas. Na teoria procura-se articular fenômenos singulares a certas constantes, sejam elas estruturais às obras, ou a certos contextos. Se retomo isso que parece evidente para qualquer pensador das humanidades é porque muitas vezes não consideramos que a mudança de cânone deve, ou deveria, implicar se não em mudanças de teoria(s), ao menos em sua revisão radical. A teoria estabelece um horizonte de leitura reproduzindo horizontes passados. Ela como que projeta para frente estruturas lidas (e projetadas) no passado. Ela tem uma tendência a repetir o cânone e a fazer com que o reafirmemos. Em resumo: a teoria tende a ser reprodutora e conservadora. O caso paradigmático da Poética de Aristóteles não só delimitou um espaço para se pensar a tragédia, a epopeia e outros gêneros de sua época, como delimitou um conjunto de obras e autores que já eram (e foram reforçados novamente por Aristóteles como sendo) de certa maneira canônicos, bem como deduziu regras e estabeleceu critérios e modos de julgamentos das obras. Se até hoje consideramos o Édipo Rei de Sófocles uma tragédia modelar, isso comprova não só a força da obra de Sófocles, mas também do 
trabalho de Aristóteles como grande pai não só da teoria literária, mas de toda a estética.

Do Renascimento ao Classicismo de um Boileau o modelo aristotélico imperou. Se no início do século XVIII, em autores como Dubos, surge a estética do gênio, depois entronizada pelo movimento Sturm und Drang, com sua valorização da originalidade e da ruptura, esse novo movimento, que culminou com as poéticas do romantismo, apenas fez com que a teoria assumisse um novo ritmo, mais acelerado, mas não menos conservador. A lógica das artes passa a ser uma lógica do choque, da ruptura e da novidade, que vai ser respondida por teorias que pensam o ser efêmero das artes (como em Baudelaire e, antes dele, em Friedrich Schlegel). Mas nem por isso novos cânones deixam de se construir. Sobretudo tendo-se em vista que as artes, com grande destaque para a literatura, passam a ter no século XIX um papel fundamental nas guerras nacionalistas, ou seja, elas passam a ser elementos simbólicos importantes tanto na construção do indivíduo moderno (burguês, mas não só), como também do discurso de estabelecimento e de autoafirmação do nacional. É verdade, no entanto, que ainda para autores chave na teoria estética, como Baumgarten e Kant, o modelo ainda era o antigo clássico. Mas, a literatura que em um autor como Goethe ainda se afirmava de um modo transnacional, passa, com o romantismo tardio, a ser cada vez mais nacionalista. Herder, um dos grande mentores intelectuais de Goethe, oscilou entre um nacionalismo inicial e um cosmopolitismo no final da vida. De 1766 em diante ele se dedicou a traduzir e compilar obras da tradição europeia, ou seja, já em Herder e, depois, com mais afinco no primeiro romantismo alemão, a tradução serve de potente alavanca em direção ao plurilinguismo e ao diálogo entre as culturas. Tratava-se então de se traduzir não ao "modo francês" (no modelo das belle infièle), ou seja, eliminando as diferenças e submetendo o outro à batuta da cultura de chegada. A noção de Weltliteratur de Goethe pode ser vislumbrada nessa conversa com seu secretário Johann Peter Eckermann: “Cada vez mais me convenço 
(...) de que a poesia é uma propriedade comum à humanidade, que por toda a parte e em todas as épocas surge em centenas e centenas de criaturas. (...) Apraz-me por isso observar outras nações e sugiro a cada um que faça o mesmo. A literatura nacional não significa grande coisa, a época é da literatura mundial e todos nós devemos contribuir para apressar o surgimento dessa época." (31 de janeiro de 1827). Kestler, que cita essa mesma passagem, comenta: "Goethe denomina de Weltliteratur o que atualmente chamamos de intercâmbio e comunicação intercultural, nos quais se manifestaria o que há em comum entre as diferentes culturas, sem que se apague a individualidade que se baseia em diferenças nacionais. No sentido prático, Weltliteratur se refere à tarefa dos escritores e poetas, que devem fomentar o intercâmbio intelectual através de traduções, resenhas, discussões e encontros pessoais." (2010) É interessante que aqui vemos um modelo ainda como que representacionista, que se baseia em identidades nacionais e na sua pretensa "representação", mas que ao mesmo tempo fomenta o diálogo e a abertura. $\mathrm{O}$ autor, por assim dizer, representaria a nação; mas Goethe tem o mérito de ter afirmado que "A literatura nacional não significa grande coisa": isso era muita coisa pra sua época de despertar nacionalista.

As teorias da literatura (com raras exceções) para além de serem eurocêntricas, são também nacionalistas, partem de cânones nacionais. Esse movimento é tão forte que ainda hoje boa parte do que é feito em pesquisa nas áreas de Letras de cada país tem a ver com uma espécie de abordagem "cultual" dos "grandes autores" pátrios. Se na Europa a teoria da literatura e das artes vivera desde o renascimento uma querelle des anciens et des modernes, por outro lado, com os conflitos nacionalistas, deflagrados sobretudo a partir das guerras napoleônicas, passa-se a viver uma querela entre as nações. Já se aceitava que os modernos eram capazes de não só competir com os antigos, mas até de ultrapassá-los. Agora a querela passara a ser no presente, entre as literaturas/culturas nacionais. Se Gottsched, no âmbito da cultura alemã, em meados do século XVIII, ainda seguia um modelo francês, já Klopstock, uma 
geração depois, buscava os tons germânicos da literatura. Com o romantismo essa visão agônica-nacionalista das artes e literatura se aprofundou. A teoria literária passou a ser também uma teoria da nação, do próprio, da ontotipologia. Dessa época do romantismo data também a fundação dos departamentos de filologia nacionais junto com muitas das Universidades europeias. A instituição universitária, intimamente ligada ao poder político, econômico e cultural, vai ser uma verdadeira máquina de criação, afirmação propaganda do cânone nacional.

Mas antes da imposição desse modelo fechado e autoritário, o romantismo de Iena apresentou uma concepção de romantização do mundo que pensava a teoria como uma espécie de medium-de-reflexão, na expressão consagrada por Walter Benjamin. A intensa produtividade intelectual realizada pelo pelos românticos alemães em diálogo crítico com os pensadores do Iluminismo justificou já em meados da década de 1790 na França, descrições do "célebre Kant" como um "homem que produziu na Alemanha, nos espíritos, uma revolução semelhante àquela que os vícios do Antigo Regime fizeram ocorrer [...] na França" (Le Moniteur, 13 Nivôse IV [03/01/1796]; apud M. Zingano 1989 5) De resto, foi o abalo na tradição que a Revolução provocou que abriu a possibilidade para a revolução intelectual. A Revolução, além disso, já trazia em si mesma a figura da inversão da hierarquia entre as ideias e a efetividade e esse aspecto foi retratado em seguida por Hegel nas suas famosas Preleções sobre a Filosofia da História com a seguinte imagem: "Desde que o sol encontra-se no firmamento e os planetas giram em torno dele, isso nunca fora visto: que as pessoas se perfilassem sobre a cabeça, ou seja, sobre as ideias [Gedanken], e construíssem a efetividade segundo elas" (apud H.J. Mähl 1985: 275). Mas, em termos das concepções teóricas que aqui interessam, essa revolução era na verdade vista de diferentes modos. Podemos pensar na "revolução" que reage às mudanças com a afirmação do próprio, típica do romantismo conservador e reacionário, assim como lembrar do conservadorismo mencio- 
nado da academia, mas também recordar justamente do grupo de Iena com sua teoria aberta da identidade, que já antecipa muitas intuições do pós-estruturalismo. Podemos ler nos fragmentos de Schlegel uma verdadeira revolução na teoria da identidade que foi muito além do elogio conservador da imitação dos Antigos. Essa teoria da identidade possui uma fantástica atualidade, que não foi de modo algum ainda recebida com a intensidade que mereceria e também deve servir de antídoto ao romantismo conservador. Essa teoria foi descrita por Walter Benjamin (1993 [1919]) sob o signo da Reflexão, ou seja, da concepção do "eu" como um jogo de constante auto-divisão, diferenciação e síntese. Essa estrutura reflexiva é típica tanto da concepção de formação como constante saída de si (ou seja, como tradução de si mesmo), como também de conceitos como o de ironia, o de romance (enquanto mistura e forma estruturante de todos os gêneros na modernidade). O que é digno de nota é que com essa forte teoria autopoietica (auto engendradora) do ser e, portanto, da literatura e da cultura de um modo geral, o "ser sem caráter" passou a ser visto como um estado indistinto do "ter caráter". A ontologia foi substituída por uma teoria do ser como jogo infinito de construção, de auto-diferenciação de si. Se Herder ainda pôde escrever, lamentando-se, nas suas Cartas "Nós alemães chegamos tarde demais. O caráter da nossa poesia é imitação", para o Schlegel dos anos 1798-99 este "chegar tarde demais" seria, na verdade, o estado natural de toda cultura. Toda cultura e toda identidade individual nasce da imitação. Assumir isto implica se libertar dos grilhões da ideia de "próprio" e de "autêntico" com relação a uma cultura. Trata-se aqui de destacar essa mímesis não repressora, que nem submete o objeto mimetizado, nem reduz o sujeito a resultado de seu "original", nem a uma mimese paranoica, derivada de um medo do outro. Antes, trata-se de uma visada panmimética criativa da cultura, que vê na mimese um ato também de desvio (re)criador.

As consequências da visão primeiro romântica do ser como infinita oscilação entre ser e não-ser ou ainda, entre Eu e Não-Eu só 
poderia culminar em uma concepção da cultura como espaço de circulação e multi-fecundação entre as diversas culturas. Assim como para Schlegel não se pode pensar uma obra independentemente de todas obras do mesmo autor e da intertextualidade que lhe é essencial, do mesmo modo, para ele não se pode pensar uma língua/ cultura separadamente da outra. Portanto, para essa teoria primeiro romântica também hierarquias decantadas há séculos deveriam ser não só invertidas, como também superadas. Uma delas é a que prioriza o "original" diante da sua "tradução". "Traduzir", escreveu Novalis, numa carta a A. Wilhelm Schlegel de novembro de 1797 sobre a sua tradução da obra de Shakespeare, "é tanto poetar como produzir obras próprias - e mais difícil, mais raro. Afinal de contas, toda poesia é tradução." E ele ainda arrematou, retomando o tema da competição entre as nações: "Eu estou convencido que o Shakespeare alemão é presentemente melhor que o inglês". A paz perpetua que Novalis (manifestando a faceta conservadora de seu pensamento) vislumbrara na Europa católica não valeria mais na relação agônica entre as línguas. Mas com a diferença fundamental de que esta "guerra" é produtiva e gera cultura: não é propriamente uma guerra, mas um carrefour, uma visão lúdica da relação entre as línguas/culturas que as vê como participantes de um jogo no qual todas ganham em Spielraum, âmbito de criatividade. A visão romântica da cultura europeia - e também mundial, se pensarmos nos estudos de Schlegel do sânscrito - mesmo em meio às guerras e às utopias da Paz Perpétua, reservou um caminho eficaz para o diálogo transformador entre as culturas no dispositivo constantemente "insurgente" e "revolucionário" que é a tarefa do tradutor.

Mas essas ideias românticas permaneceram como que recalcadas até Benjamin as retomar e reler nesse diapasão desconstrutor. O que imperou foi o modelo nacionalista. Só após a Segunda Guerra que esse modelo começou a enfrentar críticas de peso sendo que, até então, esse elemento nacionalista era tido como natural. Se autores como Walter Benjamin e os formalistas russos destoavam desse tom nacionalista na primeira metade do século XX, nem 
por isso eles ampliaram o cânone abarcado pela crítica e teoria literárias. É verdade que os formalistas trabalham com obras de diversos idiomas europeus ${ }^{1}$ e que Benjamin, a partir de meados dos anos 1920, paulatinamente abandonou seu germanicismo em direção à literatura e cultura francesas, mas eles de um modo geral não conseguiram olhar mais além do horizonte europeu. ${ }^{2} \mathrm{O}$ culto do "primitivismo", presente em artistas como Braque, Picasso, Nolde e Gauguin (primitivismo esse que em si era também exotizante e eurocêntrico, mas que ao menos serviu para forçar a visão da estética para além da tradição predominante do "belo" do classicismo europeu), praticamente deixou intocada teoria literária. O outro também aparece na maioria das vezes na literatura como o exótico, que serve para afirmar o próprio. Estudos como o de Ernst Fenollosa sobre a escrita chinesa, influenciaram tanto Pound como Haroldo de Campos e serviram para abrir o cânone e a teoria. Esse é um exemplo tardio de tendências que quero defender neste trabalho.

Nas últimas décadas os estudos culturais (Raymond Willians, Stuart Hall etc.) e pós-coloniais (Gayatri Chakravorty Spivak, Homi Bhabha etc.), fazem parte de um movimento complexo de glocalização onde ocorre tanto uma universalização do modelo europeu vindo do Iluminismo, numa última investida no sentido de "iluminar" todos os recantos do planeta com a razão europeia, como também a resistência a essa homogeneização, que normalmente acaba afirmando o "subalterno" novamente como como uma identidade fechada. As tentativas de democratizar e de pluralizar a cultura, na maioria das vezes vêm sob a chancela da indústria cultural (ou da indústria cultural acadêmica) e se trata mais e uma estereotipação e fabricação do "outro" em pílulas palatáveis, do que de desconstrução verdadeira dos discursos representacionistas e defensores de identidades fechadas. A abertura do cânone até agora, dentro dos referidos movimentos acadêmicos contemporâneos, tem servido para mudar o cânone e a teoria, mas essa visão cristalizada da identidade ainda é a predominante. Da mesma for- 
ma, os discursos que tendem a ser mimetizados e traduzidos ainda são produzidos nas antigas metrópoles econômicas. Ou seja, a esperada multipolaridade ou, melhor, a explosão dos discursos em sua articulação político-econômica ainda não aconteceu. A geografia que divide o mundo entre produtores e receptores de teoria e os movimentos no sentido norte-sul não foram ainda suficientemente abalados. Esse é o próximo passo que precisa ser feito.

Precisamos romper a velha da divisão de trabalho: fornecedores matéria prima X produtores de teoria/software, que agora reproduz o mapa da economia mundial. Não se trata apenas de expandir o cânone, para além do eurocentrismo, mas de criar novas teorias. Elas devem ter como um de seus desideratos uma crítica radical da razão eurocêntrica/iluminista, responsável, graças a seu conceito fatal de identidade, por uma recaída constante no fundamentalismo. A razão iluminista é eminentemente ontotipológica. Criticá-la, no entanto, não implica substituí-la pelo irracionalismo ou pela desrazão, mas sim procurar sempre radicalizar o movimento da crítica. Devemos abrir espaços para relação dialógica dos atores culturais e romper a circulação do sempre igual. A permanência desse modelo eurocêntrico na teoria (especificamente no campo das Letras) se deve não apenas por conta de uma tendência histórica à inércia e ao conservadorismo da teoria, que vimos acima, mas por outros motivos bem concretos como:

a. Meios de financiamento e de divulgação ainda concentrados nas antigas regiões metropolitanas;

b. Manutenção dos papeis na divisão de trabalho via:

1. Manutenção de um cânone eurocêntrico;

2. Autopreconceito das periferias, onde, como agravante, muitas vezes ainda impera um positivismo que vê a teoria com desconfiança;

3. Competição acirrada nas Universidades "centrais" que mantêm a luta pelo domínio teórico.

O momento agora é o de batalhar para que tanto o hardware cultural como seu software sejam pensados de modo multipolar. $\mathrm{O}$ 
modelo de diálogo cultural como um encontro de agentes culturais no qual se dá a diferenciação constante de si e do outro, deve orientar nossa visão da dinâmica cultural, e substituir a noção de encontro de Gestalten pré-formadas e fechadas que contribuem cada uma com a sua pretensa "originalidade". Essa visão móvel do ser tem que ser afirmada de modo mais radical tanto nas "metrópoles" como nas "periferias". Em ambos os casos ainda predomina uma visão nacionalista e localista que, via de regra, está reproduzindo estruturas fascistas de identidade: outrofóbicas e potencialmente outricidas. Essa visão móvel deve, portanto, ir além dos muros das universidades e se tornar patrimônio de uma humanidade pósnacional. Para isso hábitos tradicionais da teoria devem também ser abalados e superados, como seu tradicional logocentrismo e grafocentrismo. A virada icônica permite expandir a visão de literatura e do literário para além da tradição do livro. Toda uma série de dicotomias tendem a ser abaladas com esse avanço da visão plástica (móvel) da identidade como fluxo contínuo, como a dicotomia entre metrópole e periferia, o dentro e o fora, o belo e o feio, o superficial e o profundo, o próprio e o estrangeiro etc. Todos que quiserem poderão ser produtores de software, poderão, para lembrar um termo caro a Vilém Flusser, ser programadores dessa nova sociedade. As diferenças não só persistirão, como se propagarão em uma escala nunca vista: mas sem que isso resulte em construções de novas fronteiras impenetráveis. Fronteiras, sim, mas móveis, por onde hard- e softwares possam penetrar e se multiplicar, desconstruindo sempre as novas ideologias e poderes que reiteradamente - ao que tudo indica - insistimos teimosamente em reproduzir. A teoria deve ser a super-visão, a abertura de nosso olhar crítico contra essas cristalizações. Caso contrário, estaremos nos condenando a repetir os terríveis erros da razão iluminista.

Para concluir estas reflexões um tanto nômades sobre a teoria nas Letras (mas que vales pars pro toto para as humanidades no mundo de hoje), proponho que retomemos o capítulo "Nossa comunicação" do livro Pós-história, de Vilém Flusser. Flusser dese- 
nha nesse livro sua visão de um mundo que adentra a pós-história e tenta apontar maneiras de evitar que essa nova situação seja cooptada e orquestrada por pensamentos de cunho fascista. Como teórico da comunicação que era, nesse capítulo ele se dedica a descrever essa situação, do ponto de vista da comunicação. Fundamentais no seu raciocínio são os conceitos de diálogo e de circulação, que ele diferencia da seguinte maneira:

a comunicação tem dois aspectos diferentes. O aspecto produtivo de informação, e o aspecto cumulativo. A produção de informações não é criação "ex nihilo": informações novas são produzidas por síntese de informações disponíveis. Tal método sintético é chamado de "diálogo". A acumulação de informações se dá graças à transmissão de informações rumo a memórias (humanas ou outras), nas quais a informação é depositada. Tal método distributivo é chamado "discurso". Todo discurso pressupõe diálogo, porque pressupõe informação elaborada dialogicamente. Todo diálogo [...] pressupõe discurso, porque pressupõe recepção de informações a serem sintetizadas. (2011: 72-73)

Assim, toda a cultura seria "tecido comunicativo", sendo que deve existir, segundo Flusser, um equilíbrio entre diálogos e discursos, caso contrário a sociedade pode estar em perigo. O Ocidente em sua história, que consiste na criação de estratégias para produzir e acumular novas informações, teria desenvolvido dois tipos de diálogo: circulares (exemplos: mesas redondas, parlamento) e em redes (opinião pública, telefonia); e quatro tipos de discurso: teatrais (o mais antigo, vem da figura do patriarca que transmite mitos/narrativas, mas prevê contestação e revolução; exemplos: aulas, concertos); piramidais (surge ligado a sociedades mais complexas; o emissor se torna inacessível ao receptor, bloqueia o diálogo e funda a tradição; exemplos: empresas, partidos, exércitos, igrejas); árvores (surgem no Renascimento e 
tentaram reintroduzir o diálogo, mas acabam gerando códigos só para especialistas; exemplos: ciência, artes); anfiteatrais (marcam a atualidade e vão traduzir os códigos para discursos simples e pobres; exemplos: rádio, imprensa). O autor diagnostica hoje uma predomínio dos discursos sobre os diálogos. Sob um bombardeio de discursos, afogamos na redundância. Os discursos anfitetrais são baseados em aparelhos de comunicação de massa. Se o discurso em árvore era linear, os desses aparelhos é multidimensional, superam a estrutura da história e são pós-históricos. Eles engolem a história e ejetam pós-história; como caixas-pretas, traduzem eventos em programas. Os discursos teatrais e piramidais estão em crise. Benjamin já detectara a crise da narrativa tradicional, como típica da modernidade; Flusser detecta na pós-história a crise de todas instituições "teatrais" (escolas, Faculdades, teatro etc.), e piramidais. Elas se tornaram incompatíveis com o novo tecido comunicacional. Já os discursos em árvore se proliferam e procuram se acoplar aos discursos anfiteatrais. Estes últimos programam diálogos em rede, diferentemente dos em árvore, que tendem ao código que bloqueia o diálogo. "O anfiteatro exige que a informação irradiada seja transformada dialogicamente em mingau amorfo, em 'opinião pública', a fim de servir de feedback aos aparelhos emissores. A meta dos diálogos em rede não é a produção de informação nova, mas o feedback." (2011 77-78) Hoje a democracia estaria impossibilitada, pois ela depende de um diálogo produtor de informação, tal como se tem, por exemplo, no teatro. "A sensação da solidão na massa é consequência disto. A democracia não está no programa.” (2011: 78)

Flusser conclui que a ciência deve ser reformada em sentido dialógico. Para isso, o tecido comunicológico da sociedade precisa ser alterado radicalmente. Trata-se de uma tarefa antes e mais nada política. Os diálogos circulares precisam ser reinstaurados para podermos falar de um verdadeira república. A circulação anfiteatral e o diálogo em rede, para Flusser, bloqueiam os diálogos circulares. "Para que se faça nova teoria de conhecimento intersubjetivo, é 
preciso que se disponha de espaço para a intersubjetividade. A crise atual da ciência deve ser, pois, vista no contexto da situação comunicológica da atualidade. Enquanto não houver espaço para a política, para diálogos circulares não elitários [sic; elitistas], a crise da ciência se apresenta insolúvel." (2011: 79)

De minha parte, acho que hoje, cerca de trinta anos após Flusser ter escrito essas ideias, podemos pensar em um processo de dialogização republicana que se dará tanto nas redes como em um processo de despiramidização da cultura atual. Essas pirâmides são calcadas não mais apenas nas instituições detectadas por Flusser, mas nos Estados ou blocos. Um modo radical de diálogo em rede (mas que não se reduza ao simples feedback, como diagnosticou Flusser com razão) e circular, ou seja, não hierarquizado e verdadeiramente integrador e plural, é um horizonte possível com os meios de que já dispomos. Eles precisam ser reapropriados e realocados no sentido da democratização e da res-pública. O estabelecimento de uma verdadeira circulação, tradução de si e do outro em redes dialógicas, essa é a tarefa que temos diante de nós. No âmbito teórico, essa revolução implica que os discursos serão constantemente retroalimentado por diálogos circulares e em rede. Essa multipartição permitirá também uma politização da teoria, que deverá ser plasmada a partir das questões prementes em cada local. O diálogo será alimentado pela diferença (entre locais) e os discursos não mais serão impostos em via de mão única e desprovidos de relação com as questões locais. Esse panorama dinâmico do diálogo acadêmico deve prever também uma maior porosidade com outros discursos. Muitas resistências, derivadas de hábitos de pensamento, mas sobretudo de aspectos institucionais e de poderes arraigados, terão que ser vencidas. Mas, de certa forma, a sobrevivência do pensamento não-fascista depende também de encararmos essa tarefa. Esse novo design e prática do diálogo devem ser urgentemente implementados. 


\section{Notas}

1. Mas essa escola, assim como a escola estruturalista, não superam o eurocentrismo, apesar de não ser nacionalista, e só o último Derrida tenta se livrar desse eurocentrismo.

2. Uma exceção na obra de Benjamin foi a bela resenha que ele fez de uma exposição de pinturas chinesas que ele observou na Bibliothèque Nationale de Paris em 1937. No compte rendu dessa exposição, ele destacou a concepção eminentemente escritural que o proprietário da coleção, J.-P. Dubosc, possuía dessa pintura; concepção essa que ele talhara à luz dos escritos de Paul Valéry (Benjamin 1972 603). Benjamin desenvolve aí uma interessante teoria da caligrafia chinesa como fusão de imagem pintada e escrita.

\section{Bibliografia}

BENJAMIN, W. Gesammelte Schriften. Eds.: R. Tiedemann; H. Schweppenhäuser. Frankfurt a.M.: Suhrkamp, vol. IV: Kleine Prosa. Baudelaire Übertragungen, 1972.

. O Conceito de Crítica de Arte no Romantismo Alemão, trad. pref. e notas M. Seligmann-Silva. São Paulo: Iluminuras/ EDUSP, 1993.

FLUSSER, V. Pós-história. Vinte instantâneos e um modo de usar. São Paulo: AnnaBlume, 2011.

KESTLER, I. M. F. "O conceito de literatura universal em Goethe", in: Cult, http://revistacult.uol.com.br/home/2010/03/o-conceito-de-literatura-universal-em-goethe/ consultado em 08/07/2012. 
MÄHL, H.-J. "Der poetische Staat" in: Utopie- forschung:Interdisziplinäre Studien zur neuzeitlichen Utopie, ed. Wilhelm Voßkamp, Frankfurt am Main: Suhrkamp, 1985, vol. 3.

ZINGANO, M. "Introdução", in: Kant, À Paz Perpétua, trad. M. Zingano. Porto Alegre: L\&PM, 1989, p. 5-19.

Recebido em 30/08/2012

Aceito em 30/10/2012 